\title{
Identification of candidate genes for drought tolerance by whole-genome resequencing in maize
}

\author{
Jie Xu ${ }^{1,2 \dagger}$, Yibing Yuan ${ }^{1,2+}$, Yunbi Xu ${ }^{3,5}$, Gengyun Zhang ${ }^{4}$, Xiaosen Guo ${ }^{4}$, Fengkai Wu ${ }^{1,2}$, Qi Wang ${ }^{1,2}$, \\ Tingzhao Rong ${ }^{1,2}$, Guangtang Pan ${ }^{1,2}$, Moju Cao ${ }^{1,2}$, Qilin Tang ${ }^{1,2}$, Shibin Gao ${ }^{1,2}$, Yaxi Liu ${ }^{6}$, Jing Wang ${ }^{1,2}$, \\ Hai Lan ${ }^{1,2}$ and Yanli Lu $u^{1,2^{*}}$
}

\begin{abstract}
Background: Drought stress is one of the major limiting factors for maize production. With the availability of maize B73 reference genome and whole-genome resequencing of 15 maize inbreds, common variants ( $\mathrm{CV}$ ) and clustering analyses were applied to identify non-synonymous SNPs (nsSNPs) and corresponding candidate genes for drought tolerance.

Results: A total of 524 nsSNPs that were associated with 271 candidate genes involved in plant hormone regulation, carbohydrate and sugar metabolism, signaling molecules regulation, redox reaction and acclimation of photosynthesis to environment were detected by CV and cluster analyses. Most of the nsSNPs identified were clustered in bin 1.07 region that harbored six previously reported QTL with relatively high phenotypic variation explained for drought tolerance. Genes Ontology (GO) analysis of candidate genes revealed that there were $35 \mathrm{GO}$ terms related to biotic stimulus and membrane-bounded organelle, showing significant differences between the candidate genes and the reference B73 background. Changes of expression level in these candidate genes for drought tolerance were detected using RNA sequencing for fertilized ovary, basal leaf meristem tissue and roots collected under drought stressed and well-watered conditions. The results indicated that $70 \%$ of candidate genes showed significantly expression changes under two water treatments and our strategies for mining candidate genes are feasible and relatively efficient.

Conclusions: Our results successfully revealed candidate nsSNPs and associated genes for drought tolerance by comparative sequence analysis of 16 maize inbred lines. Both methods we applied were proved to be efficient for identifying candidate genes for complex traits through the next-generation sequencing technologies (NGS). These selected genes will not only facilitate understanding of genetic basis of drought stress response, but also accelerate genetic improvement through marker-assisted selection in maize.
\end{abstract}

\section{Background}

Drought is one of the most important environmental stresses around the world [1]. The climate changes and increasing population pose serious challenges to crop improvement. It is believed that understanding of how plants respond to drought stress at the

\footnotetext{
* Correspondence: yanli.lu82@hotmail.com

${ }^{\dagger}$ Equal contributors

${ }^{1}$ Maize Research Institute, Sichuan Agricultural University, Wenjiang 611130,

Sichuan, China

${ }^{2}$ Key Laboratory of Biology and Genetic Improvement of Maize in Southwest

Region, Ministry of Agriculture, Wenjiang 611130, Sichuan, China

Full list of author information is available at the end of the article
}

molecular level are useful for developing improved genotypes which would perform well under waterlimited conditions [2]. Maize (Zea mays spp. mays $L$.), one of the most important food crops in the world, is very sensitive to water-deficiency, especially during flowering, pollination and embryo development [3].

Previous studies reaffirmed that drought tolerance is a complex trait controlled by many genes [4]. It is important to mine candidate genes and unravel molecular mechanisms in response to drought stress in maize, which would help accelerate genetic improvement through marker-assisted selection. So far, genetic studies using strategies such as 
quantitative trait locus (QTL) mapping, subtractive hybridization (SSH), Real Time-PCR and cDNA microarray technology, have been reported in maize [2,5-8]. However, QTL identified under a specific genetic background usually show relatively small effects or even cannot be detected under other genetic backgrounds [9], and several studies have been done to integrate the results from multiple independent QTL mapping experiments to unravel genetic factors underlying complex traits [9-11].

Despite the surfeit of mapping publications, only a few QTL have been identified to date at the gene level through map-based cloning due to the complexity of the maize genome [12], resulting in largely unknown mechanisms of drought response. The next-generation sequencing (NGS) technologies, which provide direct insight into the DNA variation, have been used for genomewide sequencing (GWS), polymorphism detection and marker development, DNA methylation and histone modification, alternative splicing identification, gene expression analysis and DNA-protein interactions [13-15]. NGS has also become a vital choice for identifying candidate genes and variants underlying simple and even complex traits through linkage mapping, association mapping and other approaches [5]. A known QTL (GW5) associated with rice grain width was successfully identified using $209 \mathrm{~K}$ SNPs that were produced by whole-genome resequencing of a recombinant inbred line population [16]. Besides, transcriptome sequencing is also applied in transcriptional and post-transcriptional regulation analyses of genes under abiotic stress and global expression pattern analysis of complex genomes [17-20]. The transcriptome of maize reference genome B73 was studied using RNA-seq to compare gene expression in fertilized ovaries and basal leaf meristem tissues collected under drought-treated and well-watered conditions [17]. Moreover maize miRNAs regulating abiotic stress-associated processes and the gene networks were identified, and a gene model showing how they worked was proposed [20,21].

Finding and exploiting DNA sequence variation within a genome is of utmost importance for crop genetics and breeding. Thanks to the availability of whole-genome or transcriptome sequences in public databases and the recent advent of bioinformatics tools, mining genetic variation has become easier and more cost-effective. The objectives of this study are to 1) screen SNPs that play important roles in maize drought tolerance using genome-wide sequencing data; 2) identify corresponding candidate genes based on the identified nsSNPs and compare them with reported QTL for drought tolerance; 3 ) detect changes in expression level of these candidate genes using RNA-seq data from different maize tissues under two water treatments. The candidate genes could be the fundamental genetic resource for enhancement of maize drought tolerance, and their expression analysis and insight into molecular mechanisms would be helpful for molecular breeding towards improving abiotic stress adaptation.

\section{Results}

\section{SNPs and their distribution in maize genome}

Whole-genome resequencing was performed for 15 maize inbreds and a total of 4.6 billion (407 gigabases) sequence reads were aligned against the maize B73 reference genome using Short Oligonucleotide Alignment Program 2 (SOAP 2) [22], resulting in $85 \%$ of genome coverage on average. The detailed resequencing information was provided in Additional file 1: Table S1. A total of 6,385,011 SNPs with high quality were called from 15 maize inbreds and B73 reference genome. The number of SNPs was the most on chromosome $1(2,511,910)$ and the least on chromosome $10(1,205,225)$, accounting for $15.33 \%$ and $7.36 \%$ of the SNPs, respectively. SNP density varied among chromosomes, and chromosome 1 has the highest density with 8.34 SNPs per $\mathrm{Kb}$ and chromosome 5 has the lowest density with 7.29 SNPs per $\mathrm{Kb}$ (Table 1).

The distribution of SNPs across genomic regions was compared (Table 1). SNPs were most abundant in intergenic regions $(84.58 \%)$, followed in an order of intronic, promotor, exonic, UTR and splicing site regions. Notably, more SNPs were located in 3'-UTR $(1.12 \%)$ than in 5 '-UTR $(0.76 \%)$. Moreover, more SNPs were detected in the introns $(7.67 \%)$ than exons $(2.70 \%)$. For exonic regions, there were 232,997 synonymous SNPs, 205,214 nsSNPs, 3843 stop-gain and 883 stop-loss mutations. Synonymous SNPs were more abundant and the average non-synonymous to synonymous substitution ratio (Nonsyn/Syn ratio) was 0.42 in the exonic regions.

\section{Detection of nsSNPs and candidate genes using common variants (CV) analysis}

ANNOVAR tool was applied to filter nsSNPs [23]. Three extremely drought-tolerant lines and three droughtsensitive lines were used to detect candidate nsSNPs [24-29]. There were 105,656 and 89,263 nsSNPs sharing the same variants within drought sensitive group and drought tolerant group, respectively. The variants distributed across genome regions showed different densities between the two groups (Figure 1A and B). There were more variants located in telomeric regions than in near centromere regions, which was in accordance with the distribution patterns of genes in maize [30]. Among the variants, 499 nsSNPs $(0.24 \%)$ associated with 259 genes (266 transcripts) were different between the groups (Figure 1C). Chromosomes 1 to 9 each contained some candidate genes, while most of the candidate genes 
Table 1 Summary of SNPs and their distribution in different genomic regions

\begin{tabular}{|c|c|c|c|c|c|c|c|c|c|c|c|c|c|}
\hline \multirow[t]{2}{*}{ Chr. } & \multicolumn{2}{|c|}{ Total SNP } & \multicolumn{4}{|c|}{ Exonic region } & \multicolumn{3}{|c|}{ UTR } & \multirow{2}{*}{$\begin{array}{l}\text { Splicing } \\
\text { sites }^{\mathrm{e}}\end{array}$} & \multirow{2}{*}{$\begin{array}{l}\text { Intronic } \\
\text { region }\end{array}$} & \multirow[t]{2}{*}{ Promotor } & \multirow{2}{*}{$\begin{array}{l}\text { Intergenic } \\
\text { region }\end{array}$} \\
\hline & Number & Density $^{a}$ & Nonsyn & Syn & $\begin{array}{l}\text { Stop- } \\
\text { gain }^{\text {b }}\end{array}$ & $\begin{array}{l}\text { Stop- } \\
\text { loss }^{\mathrm{c}}\end{array}$ & 5'-UTR & 3'-UTR & $\begin{array}{c}\text { 5'-UTR/3'- } \\
\text { UTR }^{\mathrm{d}}\end{array}$ & & & & \\
\hline 1 & $2,511,910$ & 8.34 & 31,289 & 36,761 & 619 & 126 & 14,036 & 29,588 & 631 & 725 & 213,368 & 80,967 & $2,103,800$ \\
\hline 2 & $1,915,130$ & 8.08 & 25,916 & 28,767 & 442 & 108 & 10,644 & 22,370 & 402 & 567 & 150,733 & 60,545 & $1,614,636$ \\
\hline 3 & $1,862,945$ & 8.03 & 22,218 & 25,182 & 451 & 106 & 9,370 & 18,894 & 295 & 494 & 138,043 & 55,225 & $1,592,667$ \\
\hline 4 & $1,991,721$ & 8.25 & 20,323 & 21,608 & 456 & 96 & 8,740 & 17,449 & 458 & 447 & 117,866 & 54,140 & $1,750,138$ \\
\hline 5 & $1,588,421$ & 7.29 & 22,810 & 27,197 & 371 & 105 & 10,315 & 22,646 & 474 & 539 & 142,569 & 56,768 & $1,304,627$ \\
\hline 6 & $1,270,649$ & 7.51 & 16,936 & 19,001 & 308 & 77 & 7,589 & 14,610 & 375 & 424 & 98,366 & 43,059 & $1,069,904$ \\
\hline 7 & $1,367,126$ & 7.73 & 16,692 & 19,323 & 301 & 60 & 7,361 & 14,499 & 301 & 388 & 105,085 & 40,322 & $1,162,794$ \\
\hline 8 & $1,403,887$ & 7.99 & 18,411 & 20,233 & 376 & 75 & 43,688 & 16,400 & 290 & 452 & 111,501 & 46,710 & $1,145,751$ \\
\hline 9 & $1,267,997$ & 8.09 & 14,748 & 17,468 & 279 & 71 & 6,789 & 14,366 & 245 & 355 & 96,433 & 38,962 & $1,078,281$ \\
\hline 10 & $1,205,225$ & 8.02 & 15,871 & 17,457 & 240 & 59 & 5,978 & 12,369 & 120 & 287 & 83,062 & 34,006 & $1,035,776$ \\
\hline $\begin{array}{c}\text { Total/ } \\
\text { Average }\end{array}$ & $16,385,011$ & 7.95 & 205,214 & 232,997 & 3,843 & 883 & 124,510 & 183,191 & 3,591 & 4,678 & $1,257,026$ & 510,704 & $13,858,374$ \\
\hline Percentage & - & - & $1.25 \%$ & $1.42 \%$ & $0.02 \%$ & $0.01 \%$ & $0.76 \%$ & $1.12 \%$ & $0.02 \%$ & $0.03 \%$ & $7.67 \%$ & $3.12 \%$ & $84.58 \%$ \\
\hline
\end{tabular}

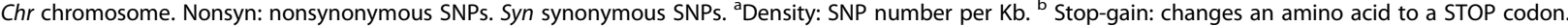

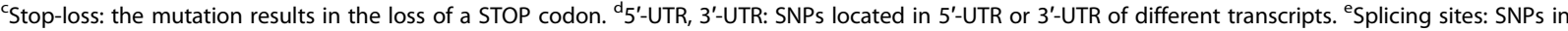
different genomic regions refer to alternative splicing.

lay on chromosomes 1 and 8. The gene transcripts selected by $\mathrm{CV}$ analysis are listed in Additional file 2: Table S2.

Among the 259 genes, 99 contained more than one nsSNPs. In particular, candidate genes GRMZM2G4665 63, GRMZM2G070038 and GRMZM2G172320 harbored 13, 12 and 12 nsSNPs with Nonsyn/Syn ratios of 0.40 , 0.25 and 0.77 , respectively. GRMZM2G466563, a member of calmodulin-binding superfamily, has been demonstrated to be an important signalling component in stress-induced cellular signal transduction pathway [4,31]. GRMZM2G172320, which encodes a keratinassociated protein participated in the formation of rigid and resistant hair shafts in mammalian [32,33], was proven to be involved in water stress signaling pathway [34].

To explore selective constrains and evolutionary divergence of these genes, the Nonsyn/Syn ratio for each candidate gene identified by $\mathrm{CV}$ analysis was also investigated using different maize germplasm sets. Among these genes, $46.33 \%$ (120 genes) only have nsSNPs in coding region. The Nonsyn/Syn ratios for candidate genes ranged from 0.03 (GRMZM2G104325) to 2.93 (GRMbZM2G071339), with an average of 0.43 , of which, 196 genes with the ratios below 0.50 while 8 genes above 1.50 . We also calculated the average Nonsyn/Syn ratio of candidate genes using the data from maize HapMap 2, which were collected from a much larger set of germplasm including wild, landrace and improved maize lines [35]. The mean Nonsyn/Syn ratio was 0.46 (0.02 -7.2). Most of the genes $(71.4 \%, 185$ out of 259 genes) were under purifying selection with the Nonsyn/Syn ratios below 0.50 (mean value: 0.23 ). In contrast, only $3.5 \%$ of the genes (9 out of 259) were under positive selection with Nonsyn/Syn ratios above 1.5 (mean value: 2.89 ).

Variants on chromosome 1 revealed by cluster analysis

To select candidate loci related to drought tolerance, SNP-based cluster analysis proposed by James Silva et al. was carried out with minor modification using all nsSNPs identified with all tested lines [36]. The nsSNPs detected on each chromosome with the tested maize inbreds were used for singular value decomposition (SVD) and Ward's minimum variance clustering. We used average variant frequency (AVF) with more than 0.8 in extremely drought-tolerant lines but less than 0.1 in extremely drought-sensitive lines to decide the number $\mathrm{K}$ of clusters. When the clustered number reached 31 , the AVFs on chromosome 1 showed distinct difference between the two groups. The AVF values were 0.010, 0.067 and 0 for the three drought sensitive inbreds, Ye478, Ji853 and B73, while they were 1, 1 and 0.837 for the three drought tolerant inbreds, LX9801, Qi319 and Tie7922, respectively. When the cluster number was less than 31, the drought-tolerant inbred Qi319 had a lower AVF value (less than 0.3) and the drought-susceptive inbred Ji853 had a modest AVF value (close to 0.50). Therefore, the 104 nsSNPs grouped in single cluster 31 on chromosome 1 were selected to represent candidate loci related to drought tolerance. A total of 41 candidate genes (44 transcripts), which were associated with the clustered SNPs, are summarized in Additional file 2: Table S2. Comparing the physical positions with chromosome bin regions of candidate nsSNPs for drought tolerance, we found that $83.65 \%$ of candidate nsSNPs were 

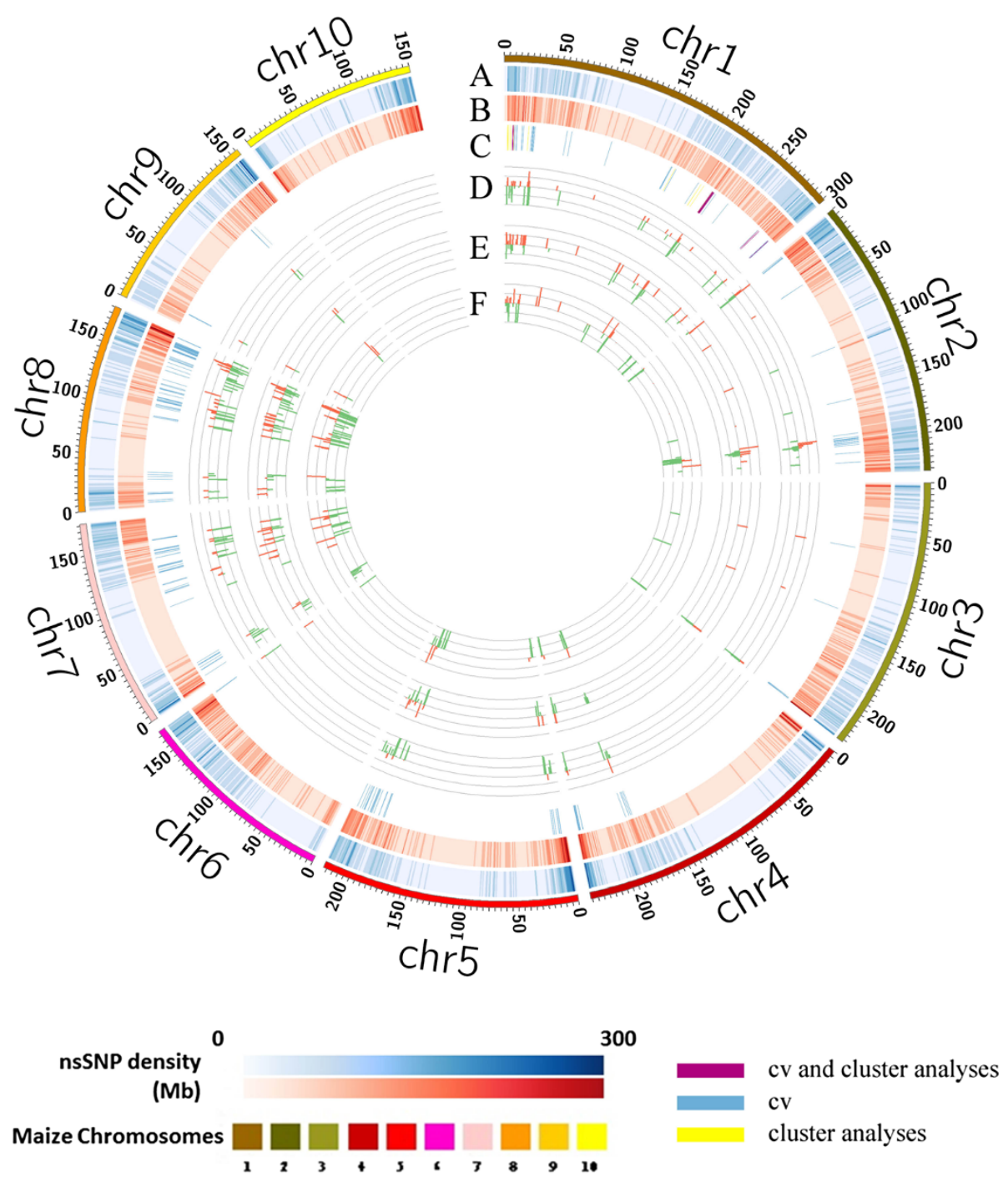

Figure 1 Distribution of nsSNPs and associated genes on maize chromosomes. Concentric circles showed aspects of the genome. Density of common nsSNPs identified in drought-tolerant maize inbreds (A) and in drought-sensitive maize inbreds (B). Genome mapping of candidate nsSNPs identified by common variants method (C). The fold change of expression level for candidate genes in ovaries (D), leaves (E) and roots (F) under water-stressed conditions compared with well-watered conditions. For Figure C, different colors indicate different strategies as shown at the bottom of right corner. For Figures D, E and F, red and green bars represent up- and down- regulated expression, respectively.

clustered in bin 1.07 (Figure 2), and these nsSNPs were related to genes involved in ABA and cytokinin catabolism, stress signal conduction and redox reaction.

Biplot was created using the clustered nsSNPs to display the relationships between drought-susceptive inbreds and the candidate nsSNPs. Figure 3 showed the biplot of variants on chromosome 1. Six inbred lines could be divided into two groups using the first and second eigenvectors, which is in accordance with their drought characteristics. The three extremely drought sensitive lines were located around the same region while the drought tolerant lines LX9801 and Qi319 located in the opposite direction of the drought sensitive lines.

\section{Comparison of candidate genes with previously identified QTL/genes}

Both of the CV and cluster analyses successfully identified candidate genes for drought tolerance. A total of 524 nsSNPs were identified by two methods, among which, 79 common variants associated with 28 genes were detected by both methods (Figure $4 \mathrm{~A}$ and B), which account for $10.8 \%$ and $68.3 \%$ of the candidate genes revealed by $\mathrm{CV}$ strategy and cluster analysis, respectively. More interestingly, we found 77 out of the 79 common variants were clustered in bin 1.07 (Figure $4 \mathrm{~A}$ and B). In addition, we compared the candidate genes with 48 QTL for drought tolerance on chromosome 1 retrieved from Gramene database (http://www.gramene.org/) and 


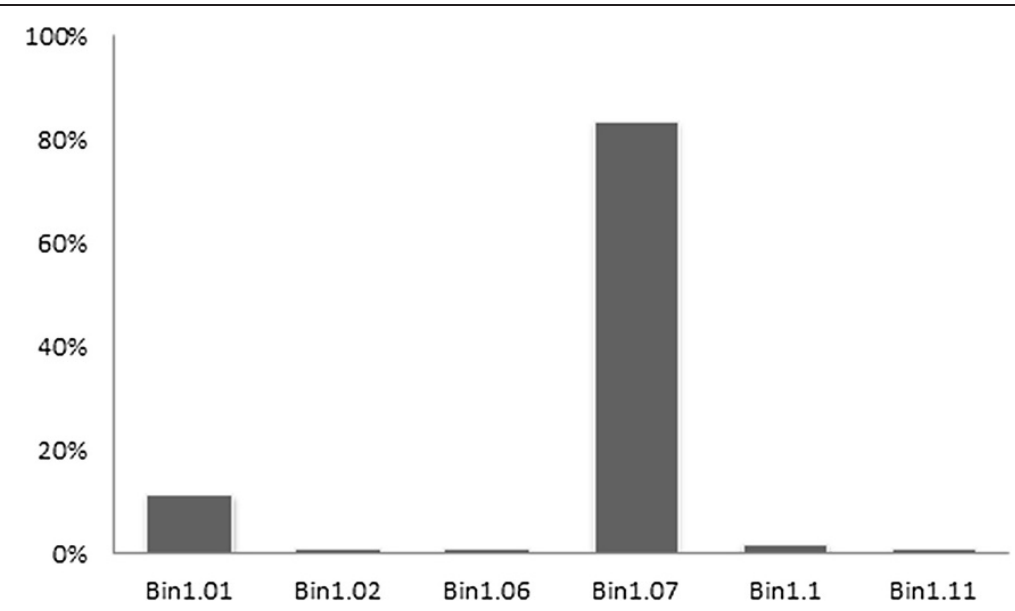

Figure 2 The cluster regions of candidate nsSNPs for drought tolerance on chromosome 1 identified by cluster analysis. X-axis represents the bin regions where the clustered nsSNPs located and Y-axis represents the percentages of nsSNPs identified by cluster analysis in each bin region on maize chromosome 1.

nine published research articles using different mapping populations and algorithms [5,37-43]. Of the 48 QTL, one for female flowering time [43], two for grain yield [37,39], one for ear number [37], one for stressed-leaf ABA content [44] and one for ASI (anthesis-silking interval) [5] were detected in bin 1.07 . The distribution of reported QTL and candidate nsSNPs on chromosome 1 are shown

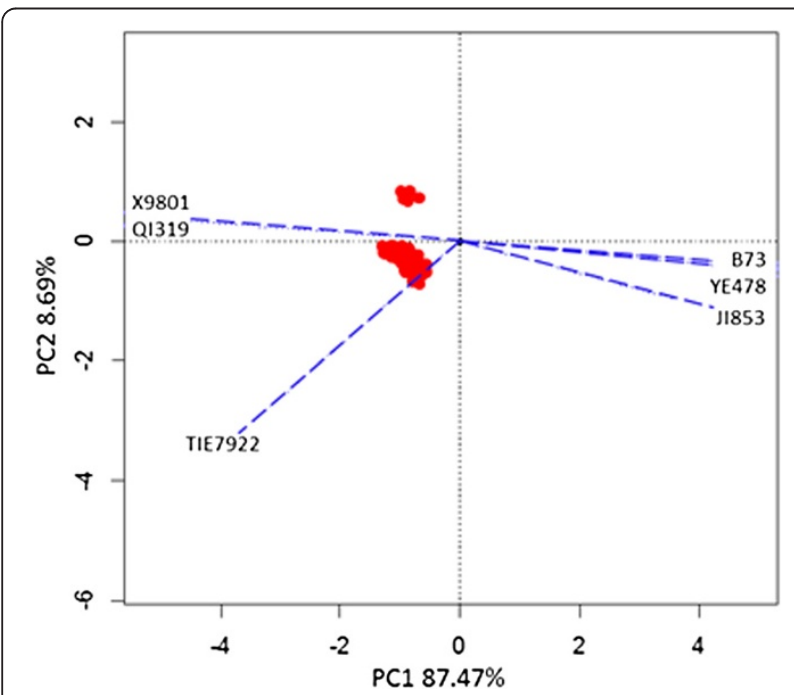

Figure 3 Biplot display of chosen variants on chromosome 1 in three extremely drought tolerance inbreds (LX9801, Qi319 and Tie7922) and three extremely drought sensitive inbreds (Ye478, Ji853 and B73). The clustered nsSNPs on chromosome 1 were selected to make the Biplot by transforming the nsSNPs into a $(0,1)$ matrix. Then the Singular Value Decomposition (SVD) was applied to the matrix with $\vee$ matrix (for nsSNPs) and G matrix (for materials) returned. The first two vectors of each matrix were used to make $\mathrm{X}$-axis and $\mathrm{Y}$-axis. The blue dotted lines indicate the vectors of the six inbred lines and red round dots represent the chosen variants on chromosome 1 . in Figure 4C. The QTL explained relatively high proportions of phenotypic variation (9\%-15\%). The 26 candidate genes identified by cluster analysis shared the same chromosomal region in bin 1.07 (Figure 2, Figure 4D). These genes were involved in plant hormone regulation, carbonhydrate and sugar metabolism, signalling molecules regulation, redox reaction and acclimation of photosynthesis to environment.

Among the candidate genes identified in bin 1.07, cytochrome P450 (GRMZM2G092823) encodes a key enzyme in ABA catabolism and plays a major regulatory role in controlling the level of ABA in plants [45]. GRMZM2G09 0264 is a Type-A Arabidopsis response regulator (ARR), which is rapidly induced by cytokinin and is a partially redundant negative regulator of cytokinin signaling [46]. GRMZM2G163437 encodes a subunit of ADP-glucose pyrophosphorylase, which is a key enzyme of the starch biosynthesis pathway [47]. GRMZM2G179063 is glucosyltransferase involved in glucuronoxylan biosynthesis and drought tolerance in Arabidopsis [48]. The putative calmodulin-binding protein (GRMZM2G466563) and leucine-rich repeat receptor-like protein kinase family protein (GRMZM2G428554) play important roles in signal transduction and drought response $[49,50]$. Besides, induction of peroxidase is a common feature of all the stress treatments [51], and GRMZM2G320269, a peroxidase 27 precursor, maybe involved in the stress response.

\section{GO enrichment analysis of selected candidate genes}

GO based functional enrichment analysis of droughttolerant candidate genes was performed by the web-based tools AgriGO (Go analysis toolkit and database for agriculture community) (http://bioinfo.cau.edu.cn/agriGO/ index.php) and AgBase (http://www.agbase.msstate.edu/). 

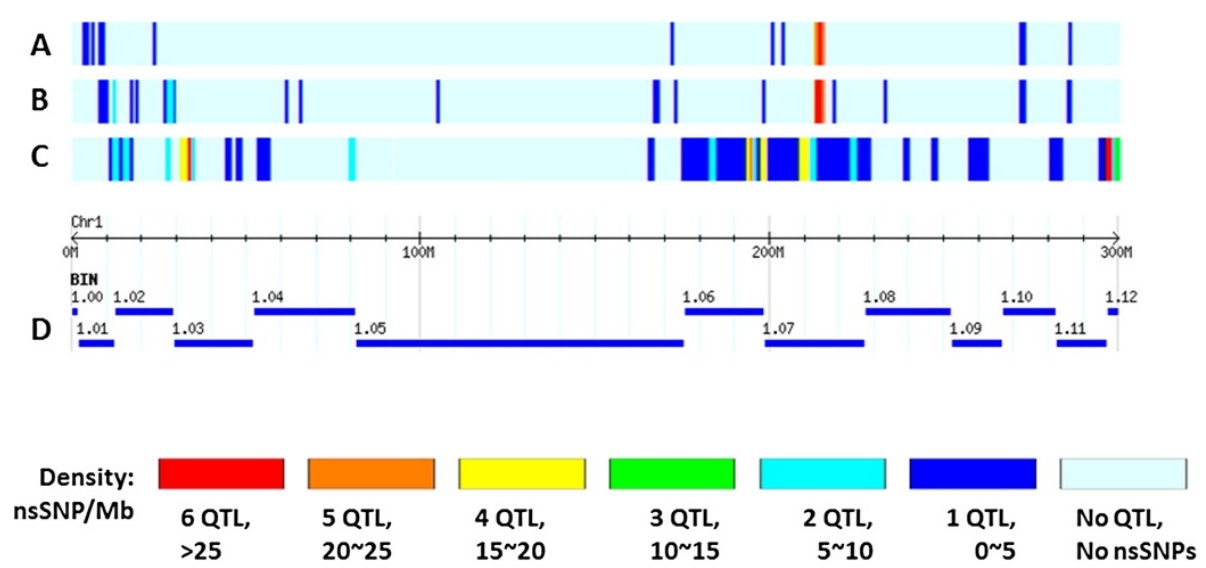

Figure 4 The densities of candidate nsSNPs by both CV and cluster analyses and reported QTL on chromosome 1 for drought tolerance. The densities of candidate nsSNPs identified by cluster analysis (A) and CV analysis (B) and reported QTL (C) on chromosome 1 for drought tolerance. (D) represents genetic distances and bin regions on chromosome 1.

The results revealed that $35 \mathrm{GO}$ terms showed significant differences between the candidate genes and all the B73 genes pre-computated as background reference, including 19 GO terms (Additional file 3: Figure S1) involved in biological processes and $16 \mathrm{GO}$ terms (Additional file 4: Figure S2) involved in cellular components. There was no GO term in the category of molecular function. The most enriched terms of biological process ontology were development- and cellular response-related, such as developmental process (GO: 0032502), multicellular organismal development (GO: 0007275), anatomical structure development (GO: 0048856), system development (GO: 0048731), response to biotic stimulus (GO: 0009607), cellular response to chemical stimulus (GO: 0070887) and response to other organisms (GO: 0051707). On the other hand, there was also a significant difference in negative regulation of biological process (GO: 0048519), negative regulation of cellular process (GO: 0048523) and chromatin modification (GO: 0016568). To the cellular component ontology, candidate genes were enriched in membrane and vesicle related cellular component including the membrane-bounded organelle (GO: 0043227), intracellular membrane-bounded organelle (GO: 0043231), cytoplasmic part (GO: 0044444), vesicle (GO: 0031982), plastid (GO: 0009536) and membrane-bounded vesicle (GO: 0031988).

A detailed comparison of biological process groups involved in drought responses to background is provided in Figure 5. With the biological process ontology, developmental process (GO: 0032502) and signalling (GO: 0023052), multicellular organismal process (GO: 0032501) and response to stimulus (GO: 0050896) were enriched for the drought response candidate genes. Meanwhile, negative regulation of biological process (GO: 0048519) and death (GO: 0016265) also showed a relatively high rate than the all given genes from reference genome B73 as background.

\section{Validation of candidate genes}

To validate whether the selected candidate genes respond to drought tolerance, we examined expression level changes of 271 candidate genes through transcriptome analysis of the roots from drought tolerant inbred AC7643, and the leaves and ovaries from drought sensitive inbred line B73 under well-watered and waterstressed conditions. The fold changes of candidate genes expression responsive to water stress in ovaries, leaves and roots are displayed in Figures 1D,E and F, respectively. A total of 262 genes revealed by $\mathrm{CV}$ and cluster strategy showed change of their expression levels in different water conditions, of which 181 genes (around $70 \%)$ changed significantly $(\mathrm{P}<0.05)$ and 77 genes had a fold change of more than two in ovaries, leaves or roots. In drought tolerant inbred AC7643, 177 genes displayed significantly different expression in roots under two water treatments, including 43 up-regulated genes and 134 down-regulated genes. The expression level of aserine/threonine-protein kinase family member (GRMZM2 G179789) substantially changed, with a 7-fold-increase under water-stress condition. A hypothetical protein (GRMZM2G050741) exhibited a more than 9-fold decrease in expression level under water-stress condition. Although the candidate genes showed different expression characters due to the different tissues and inbreds used for RNA sequencing, the relatively high rate of genes significantly altered their expression levels under waterstress condition, which indicated these candidate genes identified by $\mathrm{CV}$ and cluster strategies were associated with drought tolerance. Expression level difference of candidate genes in ovaries, leaves and roots under two water treatments and the expression change based 


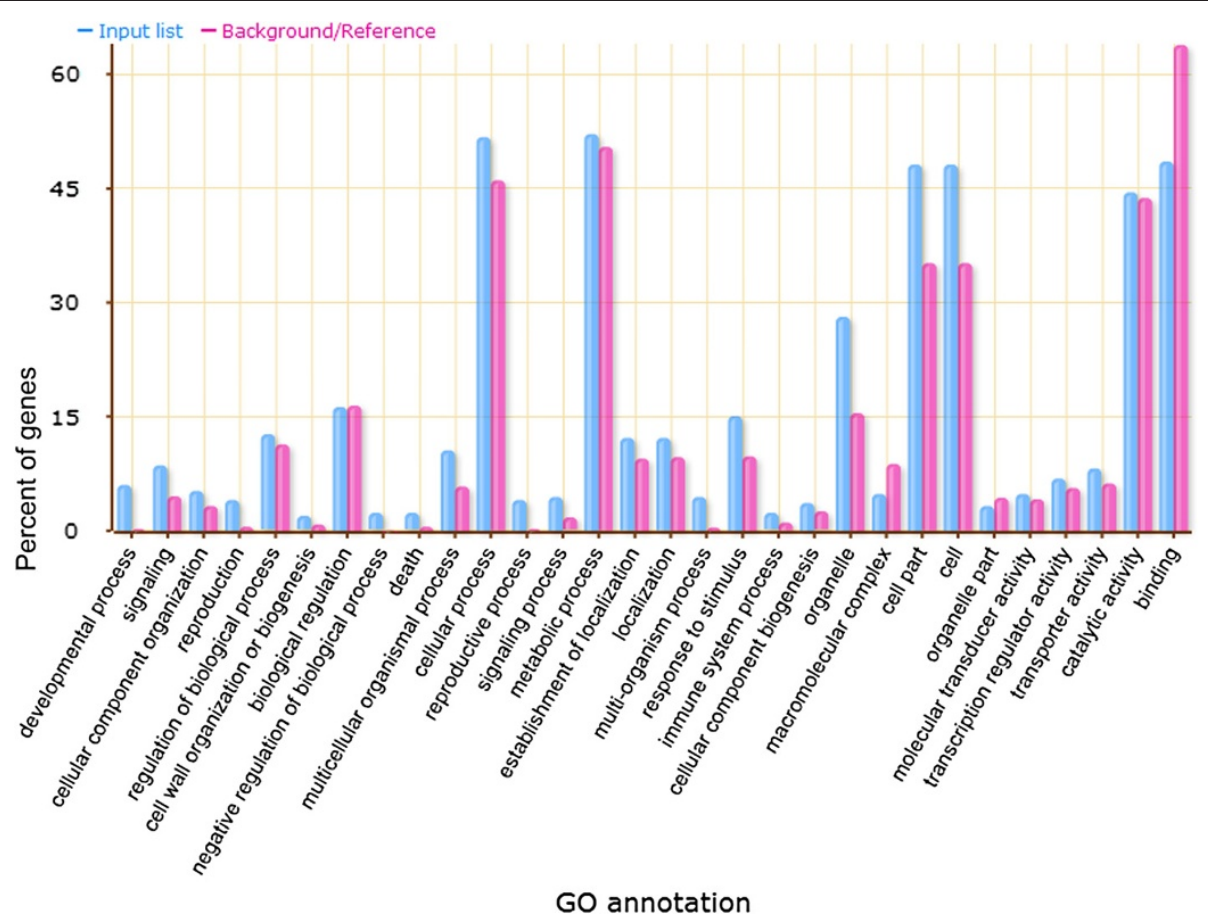

Figure 5 Flash bar chart of over represented terms for drought-tolerant candidate genes in biological process category. The Y-axis is the percentage for the input genes in different GO terms calculated by the number of genes mapped to the GO terms divided by the number of all input genes. The same calculation was applied to the reference list to generate its percentage. These two lists are represented using different custom colors. The $\mathrm{X}$-axis is the definition of $\mathrm{GO}$ terms.

hierarchical clustering are shown in heat map with different colors representing relative mRNA expression (Figure 6).

\section{Validation of SNPs}

To verify the accuracy of SNPs, comparison of the 46,556 loci identified from Illumina SNP50K Chip and SNPs called from 12 resequencing inbreds were performed. The results indicated that more than $99 \%$ of SNPs were in accordance with the physical positions and genotypes. The SNP discordant rates between two datasets were presented in Additional file 1: Table S1. In addition, all the 16 inbred lines were used for SNP validation through PCR amplification and HRM validation. Five candidate genes were randomly selected for validation and corresponding five primer pairs were designed (Table 2). The HRM result of PCR amplicons for the candidate gene GRMZM2G467339 is shown in Figure 7. The two groups with SNP locus "A" in red curves and " $G$ " in green curves in 16 inbred lines were distinguished successfully. The sequence of amplicon with the SNP in "A" had a lower melting temperature compared with single base mutation of "G". The difference in melt temperature indicated the SNP existed in the chosen maize inbred lines. The HRM genotyping results also confirmed that the candidate nsSNPs were consistent with the sequences generated by NGS.

\section{Discussion}

Functional and regulatory genes for drought tolerance in maize

Plant roots have the ability to grow toward the direction of high water availability and away from that of high osmolarity (hydrotropism). Xiong et al. searched for phenotypes conferred by drought stress and identified the inhibition of lateral root development by drought stress as an adaptive response to the stress [52]. Ovaries in tissue subjected to drought stress stop growth within 1 to 2 day after pollination [53], and tolerance to water stress in female floral parts has been correlated with yield in maize [54]. Gene expression studies in maize in response to water stress have been conducted in roots [55], seedlings [56], and developing ear and tassel [57]. In the study, transcriptome analysis of leaves, ovaries and roots from drought sensitive inbred and tolerance inbred was thus performed to further validate the candidate genes and elucidate mechanisms for its regulation.

The response of plants to drought stress is very complex and involves lots of genes and pathways related to diverse mechanisms $[4,9,58,59]$. However, some secondary physiological traits have been investigated as a drought tolerance measurement and some universal genes, such as NAC transcription factors, are involved in abiotic stress response in different varieties and even species $[60,61]$. This provides us an opportunity to mine important universal drought 


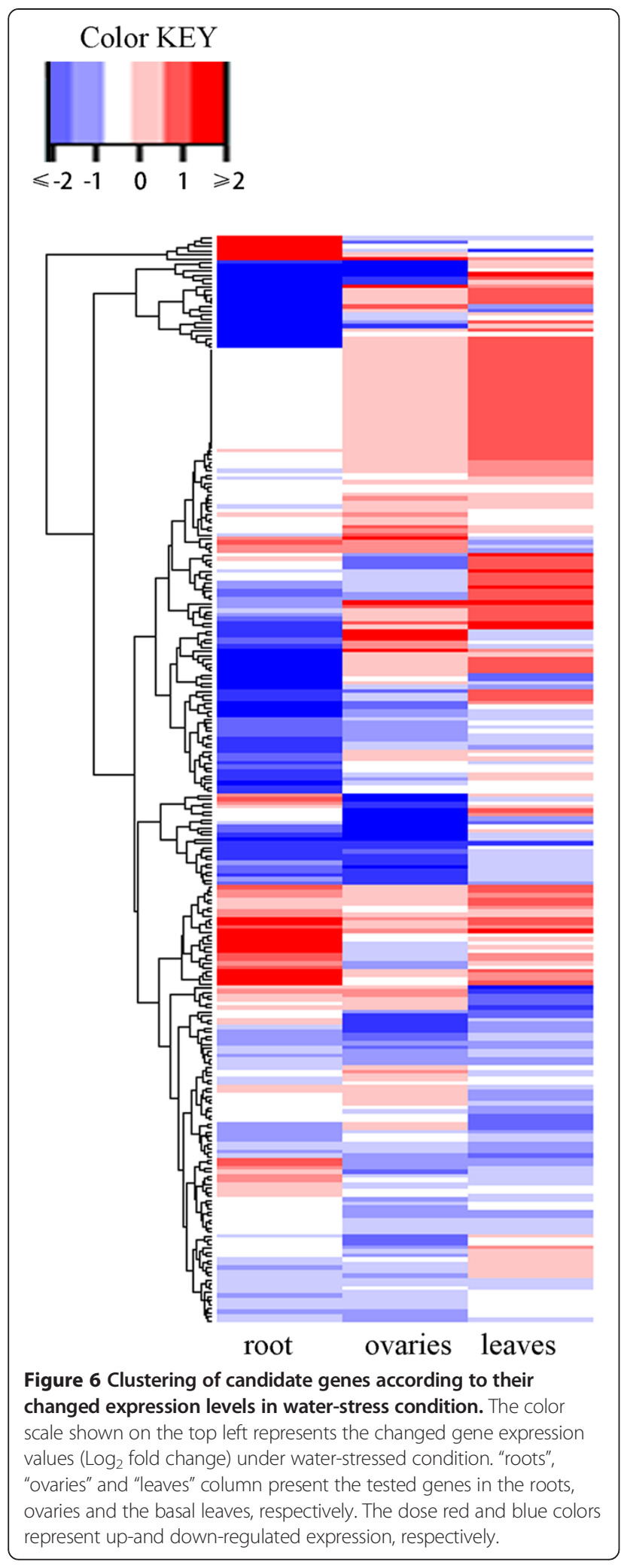

response genes by assessing the variations capably inducing modification of the protein sequences in maize inbreds with different genetic backgrounds.
In this study, we identified genes involved in plant hormone regulation (especially ABA synthesis and metabolism), carbonhydrate and sugar metabolism, signalling molecules regulation and redox reaction. These genes may function as regulatory protein factors involved in the regulation of signal transduction and gene expression functioning in stress responses [62]. One of the major unresolved issues concerning the genetic architecture of abiotic stress response is whether functional variation arises from variation in core signaling components, such as transcription factor, kinases and phosphatases, or these variations are confined to effector genes, such as biosynthetic enzymes, redox regulators and heat shock proteins [63]. Gene families with essential functions (for example, ubiquitin and cellulose synthase families) in rice tended to have substantially lower Nonsyn/Syn ratios, whereas gene families that functioned in regulatory processes and signal recognition, such as disease resistance family, had higher ratios [64]. In our research, candidate genes with more than 10 nsSNPs involving in stress signaling pathway and functioning as regulators also had higher Nonsyn/ Syn ratios, which were consistent with the results in rice.

On the other hand, from an evolutionary viewpoint, more than $70 \%$ of the candidate genes were under negative selection with a relatively low average Nonsyn/ Syn ratios in both maize inbred lines population and a much larger set of germplasm including wild, landrace and improved maize lines. The result indicated that these genes possess central and essential functions and nonsynonymous mutations impacting on the genes function have been removed by purifying selection [65]. A similar result was observed in Eucalyptus camaldulensis seedlings subjected to water stress via transcriptome sequencing [66].

\section{$\mathrm{CV}$ and cluster analyses for mining candidate genes}

Recent advances in whole-genome sequencing have allowed identification of candidate genes responsible for abiotic and biotic stresses. Silva et al. used CV and principal component-biplot (PB) selection strategy to exploit whole genome sequences of 13 rice inbred lines and identify nsSNPs and candidate genes for resistance to sheath blight, a disease of worldwide significance [33]. In our study, both $\mathrm{CV}$ and cluster analyses successfully identified the candidate genes associated with drought tolerance. Gene expression studies through RNA-seq on ovaries and basal leaves of drought sensitive inbred B73 confirmed that around $80 \%$ of the candidate genes showed decreased or increased expression under waterstress condition [17]. Moreover, transcriptome analysis conducted on the roots of drought tolerant inbred AC7643 validated $65.7 \%$ of candidate genes displayed 
Table 2 Information of the primers used for high resolution melting (HRM) analysis

\begin{tabular}{|c|c|c|c|c|}
\hline Primers & Target gene (ID) & $\begin{array}{l}\text { Product size } \\
\text { (bp) }\end{array}$ & $\begin{array}{l}\text { Annealing temperature } \\
\qquad\left({ }^{\circ} \mathrm{C}\right)\end{array}$ & Primer sequence $\left(5^{\prime}-3^{\prime}\right)(b p)$ \\
\hline \multirow[t]{2}{*}{1} & GRMZM2G072292 & 88 & 62 & F: GCAAGCGGGGACATGAGC \\
\hline & & & & R: TCTTGGAGAAGCCCAGCGA \\
\hline \multirow[t]{2}{*}{2} & GRMZM2G055844 & 69 & 62 & F: TATGTCCAGTCAGCGAGAG \\
\hline & & & & R:GGCTATGTCCACGATCATTG \\
\hline \multirow[t]{2}{*}{3} & GRMZM2G386229 & 68 & 62 & F: GAGGCGTTCTACTCCGAG \\
\hline & & & & R: AGCGACAGGAGACAGTAC \\
\hline \multirow[t]{2}{*}{4} & GRMZM2G467339 & 90 & 59 & F: GTATGTCTTAATAGGTATGTCTCA \\
\hline & & & & R: GTACACCCGATGTTCTTC \\
\hline \multirow[t]{2}{*}{5} & GRMZM2G109448 & 70 & 60 & F: GCTGTCTCATCCTCATCG \\
\hline & & & & R: CCAATCTGTGAAGAAGTGAAG \\
\hline
\end{tabular}

significantly different expression under water-stressed conditions, including 44 up-regulated genes and 134 down-regulated genes. Interestingly, the candidate genes identified by $\mathrm{CV}$ analysis showed more significant and severe change in expression level, indicating that $\mathrm{CV}$ analysis might be more efficient than clustering. However, from methodology perspective, the procedure of $\mathrm{CV}$ analysis is somewhat tedious while cluster analysis is more systematic as described by Silva et al. [36]. Besides, cluster analysis has another advantage that the candidate loci identified can be clustered in some chromosomal regions. In our analysis, the majority of candidate nsSNPs detected by cluster analysis were located in bin 1.07, accounting for $83.65 \%$ of the total candidate nsSNPs. Compared with the reported QTL for drought tolerance, this chromosomal region (bin 1.07) harbored important QTL involving in flowering time and grain yield under water-stress condition, suggesting that cluster analysis was credible and successful in mining candidate genes for the target traits in our study. Moreover, more than $10 \%$ of the candidate genes could be identified by both methods, most of which were clustered on chromosome 1 (bin1.07). For a large number of clusters, candidate SNPs identified by both methods were almost indistinguishable [36].

\section{Functions of SNPs in different genomic regions}

SNPs were very commonly used for association studies to identify genes or genetic regions contributing to complex traits $[67,68]$. From these genome-wide researches, SNPs could be identified in almost all genomic regions to explain variation of phenotypic traits to various degrees. From the point of view of molecular level, functional SNPs can affect the phenotype by interfering both transcription level and protein synthesis [69]. It has been long considered that the SNPs on protein-coding sequences have potential effects on gene function, especially the nsSNPs that could lead to amino acid residue

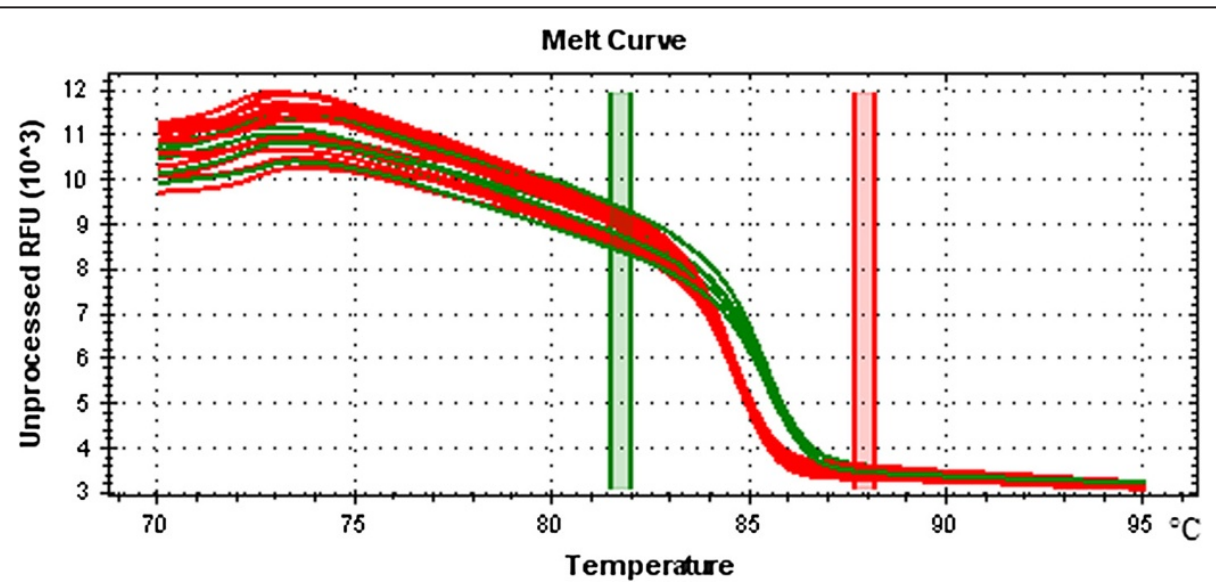

Figure 7 High resolution melting analysis (HRM) of PCR amplicons for gene GRMZM2G467339 in 16 maize inbreds. Red and green curves indicate SNP loci A and G, respectively. 
changes and altered functional or structural properties of the protein. Although the non-coding SNPs could not cause any amino acid change, they may affect transcription factor binding sites, splice sites and other functional sites in transcriptional level. In maize, $21 \%$ of the SNPs in HapMap 2 were associated with a genic region [35], which suggested that the polymorphisms in coding sequences were less than non-coding areas. Furthermore, Li et al. analyzed genic and non-genic contributions to natural variation of quantitative traits in maize and revealed that $79 \%$ of the explained variation could be attributed to trait-associated SNPs located in genes or within $5 \mathrm{~kb}$ uptream of genes [70]. This indicates that variations in genic and promotor regions would be more important in genetic resolution of complex traits. The less in numbers but more significant in terms of functions has made the nsSNPs an ideal marker type in complex trait association analysis. More than 200 genes with selected nsSNPs for resistance to sheath blight disease were detected in rice by whole-genome sequencing. In the study, we focus on the nsSNPs and drought associated candidate genes within nsSNPs were successfully detected by comparative analysis of different maize inbred lines.

\section{Genetic resources for drought tolerance in maize}

Maize is an important crop for food, feed, forage, and fuel across tropical and temperate areas of the world. Diversity studies at genetic, molecular, and functional levels have revealed that tropical maize germplasms, landraces and wild relatives harbor a significantly wider range of genetic variation. Landraces from dry habitats have been used successfully in breeding for water limited environments, and wild species and progenitors of our cultivated crops were always on the agenda as possible donors for drought tolerance [71,72].

From an evolutionary perspective, drought is an important abiotic stress that influences yield with strong interactions between genes and environment [73], which was also an important evolutionary force responsible for population diversification in some species [74]. Plants exhibit morphological and physiological adaptations to cope with environmental stresses. However, evidence for selection (natural or artificial) of drought tolerance has rarely been examined in maize. Many researches have indicated that, the ancestor of maize, teosinte, is a drought tolerant grass while domesticated landraces and inbred lines have differentiated in drought tolerance. As a result, some landraces and inbred lines are drought tolerant while others are drought susceptible. Back to the process of domestication, drought tolerance might be selected together with plant productivity in farming practice, and comparing with wild type, domesticated plants reduced defense ability exposure to biotic and abiotic stresses (which was identified in sunflower but has not been reported in maize) $[75,76]$. Therefore, identifying more drought tolerance genes and exploring the nature of drought tolerance may open new avenues for their use in maize improvement.

The advent of whole genomics technologies provides necessary tools for identifying the key gene networks that respond to drought stress [77]. Based on all available knowledge for the traits related to yield and drought tolerance, randomly dispersed QTL, trans-genes or both can be accumulated into elite genotypes through "breeding by design" [15,78]. Better understanding of the genetic bases of the secondary drought tolerance traits and analysis of allelic variation at the corresponding loci would enable the breeders to design new ideotype crops.

\section{Conclusions}

A total of 524 nsSNPs were selected by $\mathrm{CV}$ analysis and clustering using B73 reference genome and wholegenome resequencing of 15 maize inbreds with various drought characteristics. Two hundred seventy one drought-tolerant candidate genes corresponding to the candidate nsSNPs were identified, which involved in a variety of physiological and metabolic pathways in response to the water stress. GO based function analysis and comparison of candidate genes with reported drought associated QTL indicated that these candidate genes were notably associated with drought tolerance. Furthermore, about $70 \%$ of candidate genes showed significantly expression change under two water conditions by transcriptome analysis of fertilized ovaries, basal leaves and roots. Two methods used in the study are efficient approaches for detecting candidate genes underlying complex traits, including drought tolerance. Results from this study also provide a foundation for future basic research and marker-assisted breeding for improving drought tolerance in maize.

\section{Methods}

\section{Plant materials and DNA extraction}

A total of 16 maize inbred lines were selected based on their drought responses identified in our previous experiments [61] and other reports [24-26] based on selection criteria such as grain yield, anthesis-silking interval and leaf senescence under well-watered and water-stressed environments (Table 3). Among them, maize inbred lines B73, Ye478 and Ji853 were extremely droughtsensitive, while LX9801, Qi319 and Tie7922 were extremely drought-tolerant. Besides, 10 maize inbred lines with moderate drought sensitive tolerance were also used in the study. These materials were chosen from different heterotic groups, Stiff Stalk (SS) and non-Stiff Stalk (NSS) [70,71] and heterotic group containing tropical or subtropical maize inbreds (TST). Genomic DNA 
Table 3 Maize inbred lines used in the study

\begin{tabular}{|c|c|c|c|c|c|c|c|}
\hline Name & Pedigree & Origin & $\begin{array}{l}\text { Drought tolerance } \\
\text { characteristics }\end{array}$ & Selection criteria & References & $\begin{array}{l}\text { Heterotic } \\
\text { groups }\end{array}$ & Adaptation \\
\hline AC7643 & Unknown & CIMMYT & Moderate tolerance & $\begin{array}{l}\text { NDVI, ASI, LS, CC, RC, } \\
\text { GY, GYC }\end{array}$ & {$[5,61]$} & TST & $\begin{array}{l}\text { Tropical/ } \\
\text { subtropical }\end{array}$ \\
\hline CML206 & $\begin{array}{l}\text { [EV7992\#/EVPO44SRBC3]\#BF37SR-2- } \\
\text { 3SR-2-4-3-BB }\end{array}$ & CIMMYT & Moderate sensitive & ASI, LS, GY, GYC, PH & {$[25]$} & TST & $\begin{array}{l}\text { Tropical/ } \\
\text { subtropical }\end{array}$ \\
\hline Ye478 & U8112/Shen5003 & China & Extremely sensitive & $\begin{array}{l}\text { ASI, LS, GY, GYC, PH, } \\
\text { RWC }\end{array}$ & {$[25,26]$} & SS & Temperate \\
\hline Dan598 & $\begin{array}{l}\text { (Dan340/Danhuang 1 1)/(Danhuang02/ } \\
\text { Dan599) }\end{array}$ & China & Moderate tolerant & ASI, LS, GY, GYC, PH & {$[25]$} & NSS & Temperate \\
\hline Si287 & $444 / 255$ & China & Moderate tolerant & ASI, LS, GY, GYC, PH & {$[25]$} & SS & Temperate \\
\hline Ji853 & (Huangzao4/Zi330)/Zi330 & China & Extremely sensitive & ASI, RWC, MDA, EC & {$[27]$} & NSS & Temperate \\
\hline LX9801 & Ye $502 \times \mathrm{H}_{2} 1$ & China & Extremely tolerant & ASI, LS, GY, GYC, PH & {$[25]$} & SS & Temperate \\
\hline Qi319 & American hybrid P78599 & China & Extremely tolerant & ASI, LS, GY, GYC, PH & [25] & NSS & Temperate \\
\hline Tie7922 & American hybrid P3382 & China & Extremely tolerant & ASI, LS, GY, GYC, PH & {$[25]$} & SS & Temperate \\
\hline $\operatorname{Han} 21$ & American hybrid P78599 & China & Moderate tolerant & ASI, LS, GY, GYC, PH & {$[25]$} & NSS & Temperate \\
\hline Zheng22 & (Duqing/E28)/Lujiukuan & China & Moderate sensitive & ASI, LS, GY, GYC, PH & {$[25]$} & SS & Temperate \\
\hline $\mathrm{Ji} 419$ & $\mathrm{Si419/(B68HT/Mo17)}$ & China & Moderate sensitive & ASI, LS, GY, GYC, PH & [25] & NSS & Temperate \\
\hline ES40 & Landrace Linshuidadudu from Sichuan & China & Moderate sensitive & ASI, PH, EC, GY & [24] & SS & Subtropical \\
\hline 81565 & (Huobai/Jing03)/(S2/Heibai94) & China & Moderate tolerant & $\mathrm{ASI}, \mathrm{PH}, \mathrm{EC}, \mathrm{GY}$ & [24] & TST & $\begin{array}{l}\text { Tropical/ } \\
\text { subtropical }\end{array}$ \\
\hline X178 & Selected from an introduced hybrid & China & Moderate tolerant & ASI, PH, EC, GY & [24] & SS & Temperate \\
\hline$B 73$ & BSSS & China & Extremely sensitive & RWC, LAI, RWC & {$[28,29]$} & SS & Temperate \\
\hline
\end{tabular}

SS Stiff stalk heterotic group with representativeness of B73. NSS Non stiff stalk heterotic group. TST heterotic group containing tropical or subtropical maize inbreds. NDVI normalized difference vegetation index. ASI anthesis-silking interval. LS leaf senescence. CC chlorophyll content. $R C$ root capacitance. GY grain yield. GYC grain yield components. $P H$ plant height. RWC relative water content. MDA maleic dialdehyde. $E C$ electric conductivity. $L A I$ leaf area index.

was extracted from 2-week old seedlings using CTAB method.

\section{Maize genome sequencing, SNP calling and nsSNP identification}

Sequences were generated for maize lines while pairedend libraries were constructed according to the Illumina manufacturer's instructions. Whole-genome resequencing was performed on Illumina Hiseq 2000 platform for 15 maize inbreds and a total of 4.6 billion ( 407 gigabases) sequence reads were aligned against the maize B73 reference genome (www.maizesequence.org, Release 5b) using SOAP 2 [22] (http://soap.genomics.org.cn/) which is a widely used reads alignment tool. There were around 1.8 billion reads were uniquely mapped onto B73 reference genome, with average of 0.12 billion reads for each maize inbred (Additional file 1: Table S1). SNP calling and validation were performed as Chia et al. [35]. Sequencing and SNP calling were carried out at BGI (Shenzhen, China). The nsSNPs within the genes were filtered using ANNOVAR tool [23] that can be used to functionally annotate a list of genetic variants including intronic, exonic, intergenic, 5'/3'-UTR, splicing site and upstream/downstream variants. Promotor sequences were determined at $2 \mathrm{~Kb}$ upstream of transcription initiation site.

\section{Identification of nsSNPs in candidate drought tolerance genes}

Common variants (CV) analysis and SNP based cluster analysis proposed by James Silva et.al [36], with minor modification, were used separately to identify nsSNPs and their associated candidate genes for maize drought tolerance. The CV analysis for filtering candidate genes was taken as following steps: 1) screening SNPs which were common within the two groups containing three extremely drought-tolerant maize inbreds (LX9801, Qi319 and Tie7922) and three drought-sensitive inbreds (B73, Ye478 and Ji853), respectively; 2) selecting candidate nsSNPs that were different between two groups for drought tolerance; 3) identifying associated candidate genes for maize drought tolerance using the selected nsSNPs.

To identify efficiently nsSNPs related to drought tolerance, SNP based cluster analysis was also carried out using all nsSNPs detected from all tested lines. The strategy includes the following steps. 1) Remove common variants across the tested materials and transform the remaining nsSNPs into a $(0,1)$ matrix. At each locus, variant frequency was denoted by " 0 " if the allele was the same with that in B73 reference genome representing drought-sensitive line; otherwise it was denoted by 
“1". 2) Singular Value Decomposition (SVD) was applied to standardize variant frequencies in the matrix. The SVD procedure returned three matrixes, V (for nsSNPs), $\mathrm{D}$ (diagonal containing eigenvalues) and $\mathrm{G}$ (for materials). Ward's minimum variance clustering was performed using V matrix in SAS software (Release 9.3; SAS Institute, Cary, NC, USA). 3) For each cluster identified in step 2, the average values of variant frequencies were calculated for the 16 maize inbreds. The single cluster with AVF $>0.8$ in extremely drought-tolerant lines but $<0.1$ in extremely drought-sensitive lines were selected for each chromosome. 4) Screen significant nsSNPs based on step 3 , and identify the corresponding candidate genes for drought tolerance. 5) Create GGEbiplot display using clustered nsSNPs through GGEBiplotGUI package of $\mathrm{R}$ program.

\section{Gene ontology (GO) analysis of selected candidate genes} Candidate genes were submitted to AgriGO (Go analysis toolkit and database for agriculture community) (http:// bioinfo.cau.edu.cn/agriGO/index.php) and AgBase (http:// www.agbase.msstate.edu/) for gene ontology analysis [79]. Singular enrichment analysis (SEA) was used to select enrichment GO terms (http://bioinfo.cau.edu.cn/agriGO/ analysis.php) with the maize reference genome B73 as background (Maizesequence, version: 5b). The over represented terms in three categories, biological process, cellular component and molecular function, were filtered by statistical information including Fisher's exact test and the Bonferroni for multi-test adjustment method [79].

\section{Validation of candidate genes using RNA-seq data}

To further validate the candidate genes for drought tolerance revealed by $\mathrm{CV}$ and SNP based cluster analysis, the expression level of candidate genes under two water conditions was evaluated using transcriptome analysis of drought tolerant inbred AC7643 and available RNA-seq data of drought sensitive inbred B73 (http://www.ncbi. nlm.nih.gov/sra/).

For transcriptome analysis, the seeds of maize inbred AC7643 were surface-sterilized and grew in the same nutrient solution and environment condition as reported [80]. At the three-leaf-stage, 20\% PEG were subjected for $24 \mathrm{~h}$ and the roots of inbred AC7643 under wellwatered and drought-stressed conditions were sampled for RNA extraction separately using $\mathrm{TRIzol}^{\circ}$ reagent (Invitrogen, USA), RNA sequencing were performed at BGI-Shenzhen (Shenzhen, China) using Illumina deep sequencing according to the manufacturer's instructions.

The RNA-seq data obtained using Illumina deep sequencing from leaf meristem and pollinated ovaries of drought sensitive inbred B73 under well-watered and water-stressed conditions were downloaded from the publicly available databases SRA project (SRP014792) (http://www.ncbi.nlm.nih.gov/sra/). NCBI SRA toolkit was used for data format exchanging [81]. All raw reads were then applied in the FASTX toolkit (http://hannonlab.cshl.edu/fastx_toolkit/) for reads quality control prior to mapping. The fastx_clipper and fastx_artifacts_filter programs were used to remove Illumina adapter sequences and artifactual sequences such as homopolymeric sequences. Then low quality reads with length shorter than $30 \mathrm{bp}$ or less than 33 of Phred score were discarded using the fastq_quality_trimmer. Qualified RNA-seq reads were mapped to the maize B73 reference genome (http://ftp.maizesequence.org/release-5b/) with known transcripts and annotation (http://ftp.maizesequence.org/) using programs Bowtie2 (version2.0.2) and TopHat (version 2.0.6) [82,83]. HTSeq-DEseq workflow was used for differential expression analysis [84]. A false discovery rate of 0.05 after Benjamini-Hochberg correction for multiple tests was applied. The expression heat map for candidate tolerance genes was made by the $R$ ggplot2 package.

\section{SNP validation using gene chip and HRM}

In our previous research, 12 of 15 resequencing samples were genotyped with Illumina Maize SNP50 chip, from which, 46,556 high-quality SNPs were selected and then their probe sequences were mapped to the B73 reference to get the exact physical positions. To verify the accuracy of SNPs, comparison of chip-based genotyping and SNP calling from 12 resequencing inbreds were conducted based on their physical positions. Besides, five primer pairs were designed for the five candidate genes containing target nsSNPs (Table 2), and genomic DNA of the 16 tested maize inbred lines were chosen as the templates. PCR reactions were performed on Bio-Rad CFX96 realtime PCR detection system (Bio-Rad, Inc., Hercules, $\mathrm{CA})$. The reaction volume and cycling conditions were followed by the SsoFastTMEvaGreensupermix (Bio-Rad) manual. All samples were amplified in duplicate reactions and together with a non-template control. HRM curve data was analyzed using the manufacturer's software.

\section{Additional files}

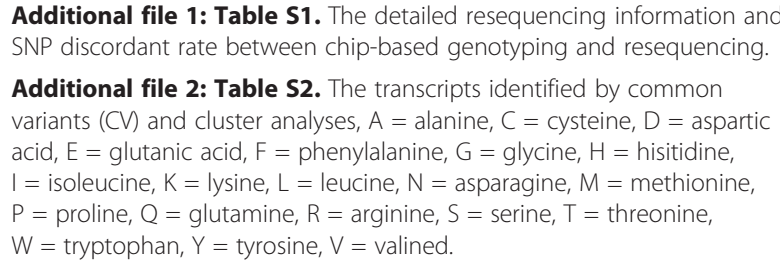

Additional file 1: Table S1. The detailed resequencing information and SNP discordant rate between chip-based genotyping and resequencing.

Additional file 2: Table S2. The transcripts identified by common variants $(\mathrm{CV})$ and cluster analyses, $\mathrm{A}=$ alanine, $\mathrm{C}=$ cysteine, $\mathrm{D}=$ aspartic acid, $\mathrm{E}=$ glutanic acid, $\mathrm{F}=$ phenylalanine, $\mathrm{G}=$ glycine, $\mathrm{H}=$ hisitidine, $\mathrm{I}=$ isoleucine, $\mathrm{K}=$ lysine $\mathrm{L}=$ leucine, $\mathrm{N}=$ asparagine, $\mathrm{M}=$ methionine, $\mathrm{P}=$ proline, $\mathrm{Q}=$ glutamine, $\mathrm{R}=$ arginine, $\mathrm{S}=$ serine, $\mathrm{T}=$ threonine, $\mathrm{W}=$ tryptophan, $\mathrm{Y}=$ tyrosine, $\mathrm{V}=$ valined.

Additional file 3: Figure S1. Hierarchical tree graph of overrepresented GO terms in biological process category generated by singular enrichment analysis. Boxes in the graph represent $\mathrm{GO}$ terms labeled by their GO ID, term definition and statistical information. The significant (adjusted $P<=0.05$ ) and non-significant terms are marked with color 
and white boxes, respectively. The diagram, the degree of color saturation of a box is positively correlated to the enrichment level of the term. Solid, dashed, and dotted lines represent two, one and zero enriched terms at both ends connected by the line, respectively. The rank direction of the graph is set to from top to bottom.

Additional file 4: Figure S2. Hierarchical tree graph of overrepresented $\mathrm{GO}$ terms in cellular component category generated by singular enrichment analysis. Boxes in the graph represent GO terms labeled by their GO ID, term definition and statistical information. The significant (adjusted $\mathrm{P}<=0.05$ ) and non-significant terms are marked with color and white boxes, respectively. The diagram, the degree of color saturation of a box is positively correlated to the enrichment level of the term. Solid, dashed, and dotted lines represent two, one and zero enriched terms at both ends connected by the line, respectively. The rank direction of the graph is set to from top to bottom.

\section{Competing interests}

The authors declare that they have no competing interests.

\section{Authors' contributions}

$Y L, Y X$ and TR designed this study and participated in its coordination. GP, QT, SG and HL provided samples required for sequencing. GZ, XG performed genome sequencing and SNP calling. JX, YL and YY performed the data analysis. YY, QW, FW and JW prepared the samples for sequencing and conducted the experiments. JX, YL and MC wrote the manuscript. All authors read and approved the final manuscript.

\section{Acknowledgements}

This work was supported by the Program for Sichuan Youth Innovative Research Team (2013TD0014), Foundation for the Author of National Excellent Doctoral Dissertation of China (201358), Sichuan Youth Science and Technology Foundation of China (2012JQ0003), the National Natural Science Foundation of China (No. 31271736), National High Technology Research and Development Program of China (2012AA101104), and State Key Development Program for Basic Research of China (2009CB118400). We are grateful to James Silva for the help of Biplot analysis.

\section{Author details}

'Maize Research Institute, Sichuan Agricultural University, Wenjiang 611130, Sichuan, China. ${ }^{2}$ Key Laboratory of Biology and Genetic Improvement of Maize in Southwest Region, Ministry of Agriculture, Wenjiang 611130, Sichuan, China. Institute of Crop Science, the National Key Facilities for Crop Genetic Resources and Improvement, Chinese Academy of Agricultural Sciences, Beijing 100081, China. ${ }^{4}$ BGI-Shenzhen, Shenzhen 518083, China. 5 International Maize and Wheat Improvement Center (CIMMYT), El Batan 56130, Texcoco, Mexico. ${ }^{6}$ Triticeae Research Institute, Sichuan Agricultural University, Wenjiang 611130, Sichuan, China.

\section{Received: 14 November 2013 Accepted: 17 March 2014} Published: 1 April 2014

\section{References}

1. Yang S, Vanderbeld B, Wan J, Huang Y: Narrowing down the targets: towards successful genetic engineering of drought-tolerant crops. Mol Plant 2010, 3(3):469-490.

2. Ribaut J-M, Betran J, Monneveux P, Setter T: Drought tolerance in maize. In Handbook of Maize: Its Biology. Edited by Bennetzen Jeff L, Hake Sarah C. New York: Springer; 2009:311-344.

3. Boyer J, Westgate M: Grain yields with limited water. J Exper Botany 2004, 55(407):2385-2394

4. Shinozaki K, Yamaguchi-Shinozaki K: Gene networks involved in drought stress response and tolerance. J Exper Botany 2007, 58(2):221-227.

5. Lu Y, Zhang S, Shah T, Xie C, Hao Z, Li X, Farkhari M, Ribaut JM, Cao M, Rong T: Joint linkage-linkage disequilibrium mapping is a powerful approach to detecting quantitative trait loci underlying drought tolerance in maize. Proc Natl Acad Sci 2010, 107(45):19585-19590.

6. Yue G, Zhuang Y, Li Z, Sun L, Zhang J: Differential gene expression analysis of maize leaf at heading stage in response to water-deficit stress. Bioscience Reports 2008, 28:125-134.
7. Hayano-Kanashiro C, Calderón-Vázquez C, Ibarra-Laclette E, Herrera-Estrella L, Simpson J: Analysis of gene expression and physiological responses in three Mexican maize landraces under drought stress and recovery irrigation. PloS One 2009, 4(10):e7531.

8. Marino R, Ponnaiah M, Krajewski P, Frova C, Gianfranceschi L, Pè ME, Sari-Gorla M: Addressing drought tolerance in maize by transcriptional profiling and mapping. Mol Gen Genomics 2009, 281(2):163-179.

9. Hao Z, Li X, Liu X, Xie C, Li M, Zhang D, Zhang S: Meta-analysis of constitutive and adaptive QTL for drought tolerance in maize. Euphytica 2010, 174(2):165-177.

10. Courtois B, Ahmadi N, Khowaja F, Price AH, Rami J-F, Frouin J, Hamelin C, Ruiz M: Rice root genetic architecture: meta-analysis from a drought QTL database. Rice 2009, 2(2-3):115-128.

11. Li X, Li X, Hao Z, Tian Q, Zhang S: Consensus map of the QTL relevant to drought tolerance of maize under drought conditions. Sci Agric Sin 2005 38(5):882-890

12. High throughput DNA sequencing: The new sequencing revolution, Yan J, Warburton M, Crouch J: Association mapping for enhancing maize (L.) genetic improvement. Crop Sci 2011, 51(2):433-449.

13. Delseny $M$, Han $B, H$ sing $Y l$ : High throughput DNA sequencing: the new sequencing revolution. Plant Sci 2010, 179(5):407-422.

14. Barabaschi D, Guerra D, Lacrima K, Laino P, Michelotti V, Urso S, Valè G, Cattivelli L: Emerging knowledge from genome sequencing of crop species. Mol Biotechnol 2012, 50(3):250-266.

15. Mastrangelo AM, Mazzucotelli E, Guerra D, Vita P, Cattivelli L: Improvement of Drought Resistance in Crops: From Conventional Breeding to Genomic Selection. In Crop Stress and its Management: Perspectives and Strategies. Edited by Venkateswarlu B, Shanker AK, Shanker C, Maheswari M. Netherlands: Springer; 2012:225-259.

16. Xie W, Feng $Q$, Yu H, Huang $X$, Zhao Q, Xing Y, Yu S, Han B, Zhang Q: Parent-independent genotyping for constructing an ultrahigh-density linkage map based on population sequencing. Proc Natl Acad Sci 2010 107(23):10578-10583.

17. Kakumanu A, Ambavaram MM, Klumas C, Krishnan A, Batlang U, Myers E, Grene R, Pereira A: Effects of drought on gene expression in maize reproductive and leaf meristem tissue revealed by RNA-Seq. Plant Physiol 2012, 160(2):846-867.

18. Mizuno $H$, Kawahara $Y$, Sakai $H$, Kanamori $H$, Wakimoto $H$, Yamagata $H$, Oono Y, Wu J, Ikawa H, Itoh T, Matsumoto T: Massive parallel sequencing of mRNA in identification of unannotated salinity stress-inducible transcripts in rice (Oryza sativa L.). BMC Genomics 2010, 11(1):683.

19. Deyholos MK: Making the most of drought and salinity transcriptomics. Plant Cell Environ 2010, 33(4):648-654.

20. Ding D, Zhang L, Wang H, Liu Z, Zhang Z, Zheng Y: Differential expression of miRNAs in response to salt stress in maize roots. Ann Bot 2009, 103(1):29-38.

21. Xu C, Yang RF, Li WC, Fu FL: Identification of 21 microRNAs in maize and their differential expression under drought stress. Afr J Biotechnol 2010, 9(30):4741-4753.

22. Li R, Yu C, Li Y, Lam TW, Yiu SM, Kristiansen K, Wang J: SOAP2: an improved ultrafast tool for short read alignment. Bioinformatics 2009, 25(15):1966-1967

23. Wang K, Li M, Hakonarson H: ANNOVAR: functional annotation of genetic variants from high-throughput sequencing data. Nucleic Acids Res 2010, 38(16):e164-e164.

24. Fu F, Feng Z, Gao S, Zhou S, Li W: Evaluation and quantitative inheritance of several drought-relative traits in maize. Agric Sci China 2008, 7(3):280-290.

25. Hao ZF, Li XH, Su ZJ, Xie CX, Li MS, Liang XL, Weng JF, Zhang DG, Li L, Zhang $\mathrm{SH}$ : A proposed selection criterion for drought resistance across multiple environments in maize. Breeding Sci 2011, 61(2):101-108.

26. Zheng J, Fu J, Gou M, Huai J, Liu Y, Jian M, Huang Q, Guo X, Dong Z, Wang $H$, Wang $G$ : Genome-wide transcriptome analysis of two maize inbred lines under drought stress. Plant Mol Biol 2010, 72(4-5):407-421.

27. Li F, Zhu M, Lü X: Study on drought resistance and its identification index of ordinary maize inbred lines. Seed (In Chinese) 2011, 1:31-34.

28. Chen J, Xu W, Velten J, Xin Z, Stout J: Characterization of maize inbred lines for drought and heat tolerance. J Soil Water Conserv 2012, 67(5):354-364

29. Liu XD, Li XH, Li WH, Li MS, Li XH: Analysis on difference for drought responses of maize inbred lines at seedling stage. J Maize Sci 2004, 3:019. 
30. Soderlund C, Descour A, Kudrna D, Bomhoff M, Boyd L, Currie J, Angelova A, Collura K, Wissotski M, Ashley E: Sequencing, mapping, and analysis of 27,455 maize full-length cDNAs. PLoS Genet 2009, 5(11):e1000740.

31. Zielinski RE: Calmodulin and calmodulin-binding proteins in plants. Annual Rev Plant Biol 1998, 49(1):697-725.

32. Hesse M, Zimek A, Weber K, Magin TM: Comprehensive analysis of keratin gene clusters in humans and rodents. European J Cell Biol 2004, 83(1):19-26.

33. Wu DD, Irwin DM, Zhang YP: Molecular evolution of the keratin associated protein gene family in mammals, role in the evolution of mammalian hair. BMC Evol Biol 2008, 8(1):241.

34. Yang L, Fu FL, Deng LQ, Zhou SF, Yong TM, Li WC: Cloning and characterization of functional keratin-associated protein 5-4 gene in maize. Afr J Biotechnol 2012, 11(29):7417-7423.

35. Chia JM, Song C, Bradbury PJ, Costich D, de Leon N, Doebley J, Elshire RJ, Gaut B, Geller L, Glaubitz JC: Maize HapMap2 identifies extant variation from a genome in flux. Nature Genet 2012, 44(7):803-807.

36. Silva J, Scheffler B, Sanabria Y, De Guzman C, Galam D, Farmer A, Woodward J, May G, Oard J: Identification of candidate genes in rice for resistance to sheath blight disease by whole genome sequencing. Theor App/ Genet 2012, 124(1):63-74.

37. Li XH, Liu XD, Li MS, Zhang SH: Identification of quantitative trait loci for anthesis-silking interval and yield components under drought stress in maize. Acta Bot Sin 2003, 45(7):852-857.

38. Guo J, Su G, Zhang J, Wang G: Genetic analysis and QTL mapping of maize yield and associate agronomic traits under semi-arid land condition. Afr J Biotechnol 2008, 7(12):1829-1838.

39. Ribaut JM, Jiang C, Gonzalez-de-Leon D, Edmeades G, Hoisington D: Identification of quantitative trait loci under drought conditions in tropical maize. 2. Yield components and marker-assisted selection strategies. TAG Theor Appl Genet 1997, 94(6):887-896.

40. Agrama HAS, Moussa ME: Mapping QTLs in breeding for drought tolerance in maize (Zea mays L.). Euphytica 1996, 91(1):89-97.

41. Xiao Y, Li X, George M, Li M, Zhang S, Zheng Y: Quantitative trait locus analysis of drought tolerance and yield in maize in China. Plant Mol Biol Report 2005, 23(2):155-165.

42. Welcker C, Boussuge B, Bencivenni C, Ribaut J, Tardieu F: Are source and sink strengths genetically linked in maize plants subjected to water deficit? A QTL study of the responses of leaf growth and of anthesis-silking interval to water deficit. J Exper Botany 2007, 58(2):339-349.

43. Ribaut JM, Hoisington D, Deutsch J, Jiang C, Gonzalez-de-Leon D: Identification of quantitative trait loci under drought conditions in tropical maize. 1. Flowering parameters and the anthesis-silking interval. TAG Theor Appl Genet 1996, 92(7):905-914.

44. Tuberosa R, Sanguineti M, Landi P, Salvi S, Casarini E, Conti S: RFLP mapping of quantitative trait loci controlling abscisic acid concentration in leaves of drought-stressed maize (Zea mays L.). Theor App/ Genet 1998, 97(5-6):744-755.

45. Kushiro T, Okamoto M, Nakabayashi K, Yamagishi K, Kitamura S, Asami T, Hirai N, Koshiba T, Kamiya Y, Nambara E: The arabidopsis cytochrome P450 CYP707A encodes ABA 8'-hydroxylases: key enzymes in ABA catabolism. EMBO J 2004, 23(7):1647-1656.

46. To JP, Haberer G, Ferreira FJ, Deruere J, Mason MG, Schaller GE, Alonso JM, Ecker JR, Kieber JJ: Type-A arabidopsis response regulators are partially redundant negative regulators of cytokinin signaling. Plant Cell 2004, 16(3):658-671.

47. Sulmon C, Gouesbet G, Ramel F, Cabello-Hurtado F, Penno C, Bechtold N, Couee I, El Amrani A: Carbon dynamics, development and stress responses in arabidopsis: involvement of the APL4 subunit of ADP-glucose pyrophosphorylase (starch synthesis). PLoS One 2011, 6(11):e26855.

48. Keppler BD, Showalter AM: IRX14 and IRX14-LIKE, two glycosyl transferases involved in glucuronoxylan biosynthesis and drought tolerance in Arabidopsis. Mol Plant 2010, 3(5):834-841

49. Alam MM, Sharmin S, Nabi Z, Mondal SI, Islam MS, Bin Nayeem S, Shoyaib $\mathrm{M}$, Khan $\mathrm{H}$ : A putative leucine-rich repeat receptor-like kinase of jute involved in stress response. Plant Mol Biol Report 2010, 28(3):394-402.

50. Perruc E, Charpenteau M, Ramirez BC, Jauneau A, Galaud JP, Ranjeva R, Ranty B: A novel calmodulin-binding protein functions as a negative regulator of osmotic stress tolerance in arabidopsis thaliana seedlings. Plant J 2004, 38(3):410-420.
51. Kapoor M, Sveenivasan G: The heat shock response of Neurosporacrassa: Stress-induced thermotolerance in relation to peroxidase and superoxide dismutase levels. Biochem Biophys Res Communic 1988, 156(3):1097-1102.

52. Xiong L, Wang RG, Mao G, Koczan JM: Identification of drought tolerance determinants by genetic analysis of root response to drought stress and abscisic acid. Plant Physiol 2006, 142(3):1065-1074

53. Zinselmeier C, Jeong BR, Boyer JS: Starch and the control of kernel number in maize at low water potentials. Plant Physiol 1999, 121(1):25-35.

54. Setter TL, Yan JB, Warburton M, Ribaut JM, Xu YB, Sawkins M, Buckler ES Zhang ZW, Gore MA: Genetic association mapping identifies single nucleotide polymorphisms in genes that affect abscisic acid levels in maize floral tissues during drought. J Exp Bot 2011, 62(2):701-716.

55. Poroyko V, Spollen WG, Hejlek LG, Hernandez AG, LeNoble ME, Davis G, Nguyen HT, Springer GK, Sharp RE, Bohnert HJ: Comparing regional transcript profiles from maize primary roots under well-watered and low water potential conditions. J Exp Bot 2007, 58(2):279-289.

56. Zheng J, Zhao J, Tao Y, Wang J, Liu Y, Fu J, Jin Y, Gao P, Zhang J, Bai Y, Wang G: Isolation and analysis of water stress induced genes in maize seedlings by subtractive PCR and CDNA macroarray. Plant Mol Biol 2004, 55(6):807-823.

57. Zhuang Y, Ren G, Yue G, Li Z, Qu X, Hou G, Zhu Y, Zhang J: Effects of water-deficit stress on the transcriptomes of developing immature ear and tassel in maize. Plant Cell Rep 2007, 26(12):2137-2147.

58. Shinozaki K, Yamaguchi-Shinozaki K, Seki M: Regulatory network of gene expression in the drought and cold stress responses. Current Opinion Plant Biol 2003, 6(5):410-417.

59. Yao LM, Wang $B$, Cheng $L$, Wu TL: Identification of key drought stress-related genes in the hyacinth bean. PLoS One 2013, 8(3):e58108.

60. Nakashima K, Takasaki H, Mizoi J, Shinozaki K, Yamaguchi-Shinozaki K: NAC transcription factors in plant abiotic stress responses. Biochim et Biophys Acta (BBA)-Gene Regulat Mechanisms 2012, 1819(2):97-103.

61. Lu YL, Hao ZF, Xie CX, Crossa J, Araus JL, Gao SB, Vivek BS, Magorokosho C, Mugo S, Makumbi D, Taba S, Pan GT, Li XH, Rong TZ, Zhang SH, Xu YB Large-scale screening for maize drought resistance using multiple selection criteria evaluated under water-stressed and well-watered environments. Field Crop Res 2011, 124(1):37-45.

62. Rabbani MA, Maruyama K, Abe H, Khan MA, Katsura K, Ito Y, Yoshiwara K Seki M, Shinozaki K, Yamaguchi-Shinozaki K: Monitoring expression profiles of rice genes under cold, drought, and high-salinity stresses and abscisic acid application using CDNA microarray and RNA gel-blot analyses. Plant Physio/ 2003, 133(4):1755-1767.

63. Des Marais DL, McKay JK, Richards JH, Sen S, Wayne T, Juenger TE: Physiological genomics of response to soil drying in diverse arabidopsis accessions. Plant Cell 2012, 24(3):893-914.

64. Xu X, Liu X, Ge S, Jensen JD, Hu F, Li X, Dong Y, Gutenkunst RN, Fang L, Huang L, Li J, He W, Zhang G, Zheng X, Zhang F, Li Y, Yu C, Kristiansen K, Zhang X, Wang J, Wright M, McCouch S, Nielsen R, Wang J, Wang W: Resequencing 50 accessions of cultivated and wild rice yields markers for identifying agronomically important genes. Nat Biotechnol 2012, 30(1):105-111.

65. Montoya-Burgos J: Patterns of positive selection and neutral evolution in the protein-coding genes of Tetraodon and Takifugu. PLoS One 2011, 6(9):e24800

66. Thumma BR, Sharma N, Southerton SG: Transcriptome sequencing of Eucalyptus camaldulensis seedlings subjected to water stress reveals functional single nucleotide polymorphisms and genes under selection. BMC Genomics 2012, 13(1):364.

67. Poland JA, Bradbury PJ, Buckler ES, Nelson RJ: Genome-wide nested association mapping of quantitative resistance to northern leaf blight in maize. Proc Natl Acad Sci 2011, 108(17):6893-6898.

68. Tian F, Bradbury PJ, Brown PJ, Hung H, Sun Q, Flint-Garcia S, Rocheford TR, McMullen MD, Holland JB, Buckler ES: Genome-wide association study of leaf architecture in the maize nested association mapping population. Nature Genet 2011, 43(2):159-162.

69. Reumers J, Conde L, Medina I, Maurer-Stroh S, Van Durme J, Dopazo J, Rousseau F, Schymkowitz J: Joint annotation of coding and non-coding single nucleotide polymorphisms and mutations in the SNPeffect and PupaSuite databases. Nucleic acids Res 2008, 36(suppl 1):D825-D829.

70. Li X, Zhu C, Yeh CT, Wu W, Takacs EM, Petsch KA, Tian F, Bai G, Buckler ES, Muehlbauer GJ, Timmermans MC, Scanlon MJ, Schnable PS, Yu J: Genic and 
nongenic contributions to natural variation of quantitative traits in maize. Genome Res 2012, 22(12):2436-2444.

71. Xu Y, Skinner DJ, Wu H, Palacios-Rojas N, Araus JL, Yan J, Gao S, Warburton $\mathrm{ML}$, Crouch JH: Advances in maize genomics and their value for enhancing genetic gains from breeding. Int J Plant Genomics 2009, 2009:957602.

72. Blum A: Genetic resources for drought resistance. In Plant Breeding for Water-Limited Environments. New York: Springer; 2011:217-234.

73. Fleury D, Jefferies $\mathrm{S}$, Kuchel $H$, Langridge P: Genetic and genomic tools to improve drought tolerance in wheat. J Exp Bot 2010, 61(12):3211-3222.

74. Ramirez-Valiente JA, Lorenzo Z, Soto A, Valladares F, Gil L, Aranda I: Elucidating the role of genetic drift and natural selection in cork oak differentiation regarding drought tolerance. Mol Ecol 2009, 18(18):3803-3815.

75. Xoconostle-Cazares B, Ramirez-Ortega FA, Flores-Elenes L, Ruiz-Medrano R: Drought tolerance in crop plants. Am J Plant Physiol 2010, 5(5):1-16.

76. Mayrose M, Kane NC, Mayrose I, Dlugosch KM, Rieseberg LH: Increased growth in sunflower correlates with reduced defences and altered gene expression in response to biotic and abiotic stress. Mol Ecol 2011, 20(22):4683-4694.

77. Bruce WB, Edmeades GO, Barker TC: Molecular and physiological approaches to maize improvement for drought tolerance. J Exp Botany 2002, 53(366):13-25.

78. Peleman JD, van der Voort JR: Breeding by design. Trends Plant Sci 2003, 8(7):330-334.

79. Du Z, Zhou X, Ling Y, Zhang Z, Su Z: agriGO: a GO analysis toolkit for the agricultural community. Nucleic Acids Res 2010, 38(Web Server issue):W64-W70.

80. Li Y, Sun C, Huang Z, Pan J, Wang L, Fan X: Mechanisms of progressive water deficit tolerance and growth recovery of Chinese maize foundation genotypes Huangzao 4 and Chang 7-2, which are proposed on the basis of comparison of physiological and transcriptomic responses. Plant Cell Physiol 2009, 50(12):2092-2111.

81. Leinonen R, Sugawara H, Shumway M, International Nucleotide Sequence Database C: The sequence read archive. Nucleic Acids Res 2011, 39(Database issue):D19-D21.

82. Langmead B, Trapnell C, Pop M, Salzberg SL: Ultrafast and memory-efficient alignment of short DNA sequences to the human genome. Genome Biol 2009, 10(3):R25.

83. Trapnell C, Pachter L, Salzberg SL: TopHat: discovering splice junctions with RNA-Seq. Bioinformatics 2009, 25(9):1105-1111.

84. Anders $\mathrm{S}$, Huber W: Differential expression analysis for sequence count data. Genome Biol 2010, 11(10):R106.

doi:10.1186/1471-2229-14-83

Cite this article as: Xu et al:: Identification of candidate genes for drought tolerance by whole-genome resequencing in maize. BMC Plant Biology 2014 14:83.

\section{Submit your next manuscript to BioMed Central and take full advantage of:}

- Convenient online submission

- Thorough peer review

- No space constraints or color figure charges

- Immediate publication on acceptance

- Inclusion in PubMed, CAS, Scopus and Google Scholar

- Research which is freely available for redistribution 